\title{
Global Volatility Spillover, Transaction Cost and CNY Exchange Rate Parities
}

\author{
Muhammad Ishfaq ${ }^{1 *}$ \\ Zhang Bi Qiong ${ }^{2}$ \\ Ghulam Abbas ${ }^{3}$ \\ ${ }^{1}$ Ph. D. Scholar, School of Finance, \\ Central University of Finance and Economics, \\ Beijing, China \\ ${ }^{2}$ Pofessor, School of Finance, \\ Central University of Finance and Economics, \\ Beijing, China \\ ${ }^{3} \mathrm{Ph}$. D. School of Economics and Management, \\ University of Chinese Academy of Sciences, Beijing, China; \\ Sukkur Institute of Business Administration, \\ Sindh, Pakistan \\ ${ }^{*}$ Corresponding Author
}

Doi: $10.2478 / \mathrm{mjss}-2018-0036$

\section{Abstract}

The present study examines the intertemporal association between CBOE market volatility indices (VIX), foreign exchange rates and respective bid-ask spread for four CNY exchange rate parities. For this purpose, the study utilizes the stylized EGARCH $(1,1)$ model for the period of 2011 to 2016. Results report that negative slopes of EUVIX, BPVIX, and JYVIX imply a higher level of volatility, hence improves the underlying exchange rate through appreciation, while positive slopes of VXFXI deteriorates exchange rates during the sample period. Similarly, high volatility widens bid-ask spread which, in turn, deteriorates respective exchange rate and vice versa. The market-oriented policies of China increased the forecasting capability of options volatility indexes to anticipate exchange rate dynamics from $2 \%$ to $5 \%$. This indicates that flexible exchange rate regimes lead to increase the predicting power of micro structural components. Assessments of Post-reforms in CNY exchange rate evidence the rise in volatility in financial markets of China, which may discourage investor confidence and seeks for 'flight to safety' effect. While, low volatility reduces bid-ask spread which improves underlying exchange rate. The level and variance estimates of exchange rates and spreads reveal that there exists a significant relationship with VIX indices which implies that GARCH forecasts outperform in anticipating future volatility. The volatility estimates of variances show the persistence of volatility and absence of leverage effect. Overall, this article suggests that VIX index can act as 'fear gauge' indicator and its potential direction may guide investors in anticipating the movements of CNY exchange rate parities. Moreover, outcomes provide imperative implications to monetary and financial institutions for policy framing.

Keyword: Volatility Index, Foreign Exchange, GARCH models, China

\section{Introduction}

Over the last few decades, high frequency and large magnitude of exchange rate in global foreign exchange markets have demonstrated significant and often persistent movements at both level and 
volatility that are mainly unexplained by macroeconomic fundamentals (Meese \& Rogoff, 1983), (Frankel \& Rose, 1994), (Taylor M. P., 1995), (Flood \& Taylor, 1996). The researchers of microstructure literature of the forex markets attempted to clarify the mechanism inducing these deviations from fundamentals (Frankel \& Froot, 1990), (Krugman \& Miller, 1991), (Taylor M. P., 1995), (Flood \& Taylor, 1996), (Lyons, 2001). This literature is more concerned with the micro characteristics of the forex markets, such as information transmission among market participants, agent's heterogeneous expectations and implications of such heterogeneity for trading volume and volatility of exchange rate.

Microstructure approaches enriched with order flow dynamics of exchange rates, but other determinants are understudied. The present study aims to uncover the CNY exchange rate dynamics with respect to bid-ask spread and VIX (Chicago Board Options Exchange implied volatility indices) and contributes to existing literature in several ways; First this article analyzes the impact of bid-ask spread and VIX on exchange rates; second, the association of VIX with the bidask spread; third, the connection of bid-ask spread with relevant exchange rates. Earlier literature, (Glassman, 1987), (Boothe, 1988), (Black, 1989), and (Wei, 1991) use ex-post and ex-ante foreign exchange risk measures to confirm that both variables are interrelated and find that the risk measure is positively associated with the width of bid-ask spread. Presumably, VIX considers market's perceptions of risk or a gauge to measure short-term volatility. The association between VIX, bid-ask spread and exchange rates, in turn, have imperative implications for monetary institutions and portfolio investors dealing with foreign exchange.

Traders of foreign exchange markets buy options to make profits or hedge against risk if they anticipate volatility to rise above and to write options if they anticipate lower volatility than that implied by option premiums. However, this paper also examines the proficiency of the foreign exchange markets in assessing option implied volatility by comparing the level estimates of implied volatility derived from currency options with variance estimates of foreign exchange from univariate GARCH model. If the foreign exchange market is resourceful, then the option implied volatility estimates should outperform the GARCH estimates (Pilbeam \& Langeland, 2014). The study of (Engle \& Patton, 2001) states that GARCH model forecasts should help in forecasting future volatility. However, linking variance estimates of exchange rates with level estimates of options implied volatility is in itself fascinating area of research.

Most empirical literature has focused on dynamics between VIX and equity markets. The studies (Yang Cheng Lu, 2012), (Sarwar, 2012), (Kang, Ki-Hong, \& Yoon, 2014), and (Kang, YunJung, Ki-Hong, \& Sungkyun, 2014) explored the dynamic relation between VIX and equity markets. They conclude VIX plays a significant role as fear gauge indicator for investors to forecast future movements of equity markets. However, few studies established a link between VIX and exchange rates of various currencies (Kang, Ki-Hong, \& Yoon, 2014) and (Kang, Yun-Jung, Ki-Hong, \& Sungkyun, 2014) analyzed the relation of VIX with Japanese and Korean financial markets as well as the potential direction. They suggest VIX returns are negatively linked to the JPY exchange rate but have a positive impact on the KRW. This implies that a higher level of VIX index causes appreciation in JPY but depreciates KRW. Likewise, the study (Cairns, Ho, \& McCauley, 2007) concludes that 'safe heaven' currencies appreciate with an increase in global volatility, unlike highyielding currencies adopt 'flight to safety' effect and incline to depreciate.

Although VIX is now broadly recognized as an investor fear gauge in the U. S. financial markets (Whaley, 2000) (Fleming, Ostdiek, \& Whaley, 1995), the role of VIX as an investor 'fear gauge' in Chinese foreign exchange markets has no or little attention in empirical studies. This paper bridges this gap in the literature and examines if VIX serves as an investor fear gauge in the foreign exchange markets of China. Recent fluctuations in Chinese exchange rate and growing influence of its economy in most countries, it is pertinent to investigate the integration of CNY exchange rate with global volatility indicators. This study considers the interaction of four exchange rate parities of Chinese Yuan (CNY) with respect to the United States Dollar (USD), the Japanese Yen (JPY), the Euro (EUR), and the British Pound (GBP) with global volatility index (VIX) and their corresponding volatility indices VXFXI, JYVIX, EUVIX and BPVIX as the exposure of the CNY to the dollar and other major currencies is significant (Nie, Zhang, Zhang, \& Zhou, 2015). Our paper also accommodates policy break in CNY exchange rate on $11^{\text {th }}$ August 2015 . The study finds that 
CNY exchange rate parities are globally recognized and significantly influenced by both global volatility index (VIX) and volatility index of Chinese exchange-traded funds (VXFXI) which suggest that VIX can act as 'fear gauge' indicator for investors in anticipating CNY exchange rate parities. However, the negative slopes of EUVIX, BPVIX, and JYVIX indicate that a higher level of VIX improves the appreciation of individual exchange rate, but positive slopes of VXFXI deteriorates exchange rate during the sample period. Similarly, high volatility widens bid-ask spread which deteriorates respective exchange rate, while low volatility reduces bid-ask spread which improves underlying exchange rate. The level and variance estimates of exchange rates and spreads indicate a significant relationship with VIX indices which implies that GARCH forecasts outperform in anticipating future volatility. The volatility estimates of variances show the persistence of volatility and absence of leverage effect. Post-reforms assessments evidence the rise in volatility in financial markets of China, which may discourage investor confidence and seeks for 'flight to safety'.

The rest of this paper is organized as follows. Section 2 discusses the data sources, descriptive statistics and methodology. Section 3 describes the empirical results and final Section 4 provides the conclusion.

\section{Data and Methodology}

\subsection{Data Sources}

The study investigates the impact of implied volatility and bid-ask spread on foreign exchange and also impact of VIX on bid/ask spread for four CNY parities. The empirical analysis comprises daily closing prices of Chinese National Yuan (CNY) and its bid/ask spread concerning leading currencies of the world; the United States Dollar (USD), the Euro (EUR), the British Pound (GBP) and Japanese Yen (JPY). The sample period starts from March 16, 2011, to November 9, $2016 .{ }^{1}$ Our paper also accommodates policy break in CNY exchange rate on $11^{\text {th }}$ August $2015 .{ }^{2}$ However, the sample is divided into three parts; full sample, pre-reforms, and post-reforms. The FX and bidask data are provided by 'Bloomberg' which improves the reliability of analysis. Other than FX and spread values, the study uses five major option implied volatility (VIX), VXFXI, BPVIX, JYVIX, and EUVIX. The data source stems from Chicago Board of Options Exchange (CBOE). The implied volatility index (VIX) is the trademark of $\mathrm{CBOE}$, and its calculations are based on the options written on S\&P 500 index (SPX). Implied volatility defined as the market's expectation for the remaining life of the options (about 30 days), also known as 'investor's fear-gauge index.' However, VIX is calculated for equity exchanges, exchange-traded funds (ETF), currencies, commodities, and so forth. This study considers implied volatility of three currencies FX Euro Volatility Index (EUVIX), FX Yen Volatility Index (JYVIX) and FX British Pound Volatility Index (BPVIX), while S\&P 500 index (SPX) and China ETF Volatility Index (VXFXI) represent as a proxy of USD and CNY in this study as these are not published by CBOE.

\subsection{Descriptive Statistics}

Table 1 reports the descriptive statistics of VIX indices, CNY exchange rates and respective bid-ask spread concerning USD, EUR, GBP, and JPY. VIX exhibited highest standard deviation (market volatility of SPX), which means highest price change. The positive values of skewness in VIX also show increased volatility. The exchange rate of USD/CNY contains smaller standard deviation (least volatile) and positively skewed (positive returns). This positive skewness is associated with appreciation trend in later periods of USD/CNY parity as shown in level series of exchange rates

\footnotetext{
${ }^{1}$ The CBOE started to calculate China Exchange Traded Fund's Volatility Index (VXFXI) since March 16, 2011.

${ }^{2}$ The reform of the CNY exchange rate announced on 11 August 2015 and consequent $2 \%$ devaluation in the CNY/USD exchange rate stunned the markets. This reform is adopted toward more marked-based exchange rate to regime to be part of SDR (Special Drawing Rights) basket as per IMF report in early August, 2015 and also concerned due to the economic backdrop in the stock market crash, real GDP growth slowdown, and persistent capital outflows.
} 
(figure 1). Most exchange rate parities show negative skewness due to depreciation trend in CNY exchange rates which is visible in figure 1. This differential trend in CNY exchange rate parities and fluctuations in market volatility indices highlights the need to investigate individual association. However, bid-ask spread is highly volatile and comprises positive skewness. Excess kurtosis coefficients have significant values, specifying that outliers may have arisen with a probability higher than a normal distribution. Accordingly, the Jarque-Bera test rejected the null hypothesis of normal distribution for all sample returns at the $1 \%$ significance level.

However, the employment of GARCH models is subject to some assumptions which are compulsory before applying the model. Empirically it is found that asset or stock prices are nonstationary, but their log differences are stationary. Therefore, raw series are transformed into returns (Kang, Ki-Hong, \& Yoon, 2014).

$X_{t}=\left(\log P_{t}-\log P_{t-1}\right) * 100$

The ADF statistics and figures indicate that log-return series are free from the unit root and their mean returns are located around zero. The average log-return of all the indices looks meanreverting with zero return like any other indices (presented in log-return figures). Another essential assumption of $\mathrm{GARCH}$ models is the presence of $\mathrm{ARCH}$ effect in time series. The figures in Appendix of the log-return series visibly show the pattern of volatility clustering and ARCH effect which motivates to employ GARCH model. Moreover, the transformation of level series into return series removes the problem of multicollinearity employing Variance Inflation Factor (VIF) test. ${ }^{3}$

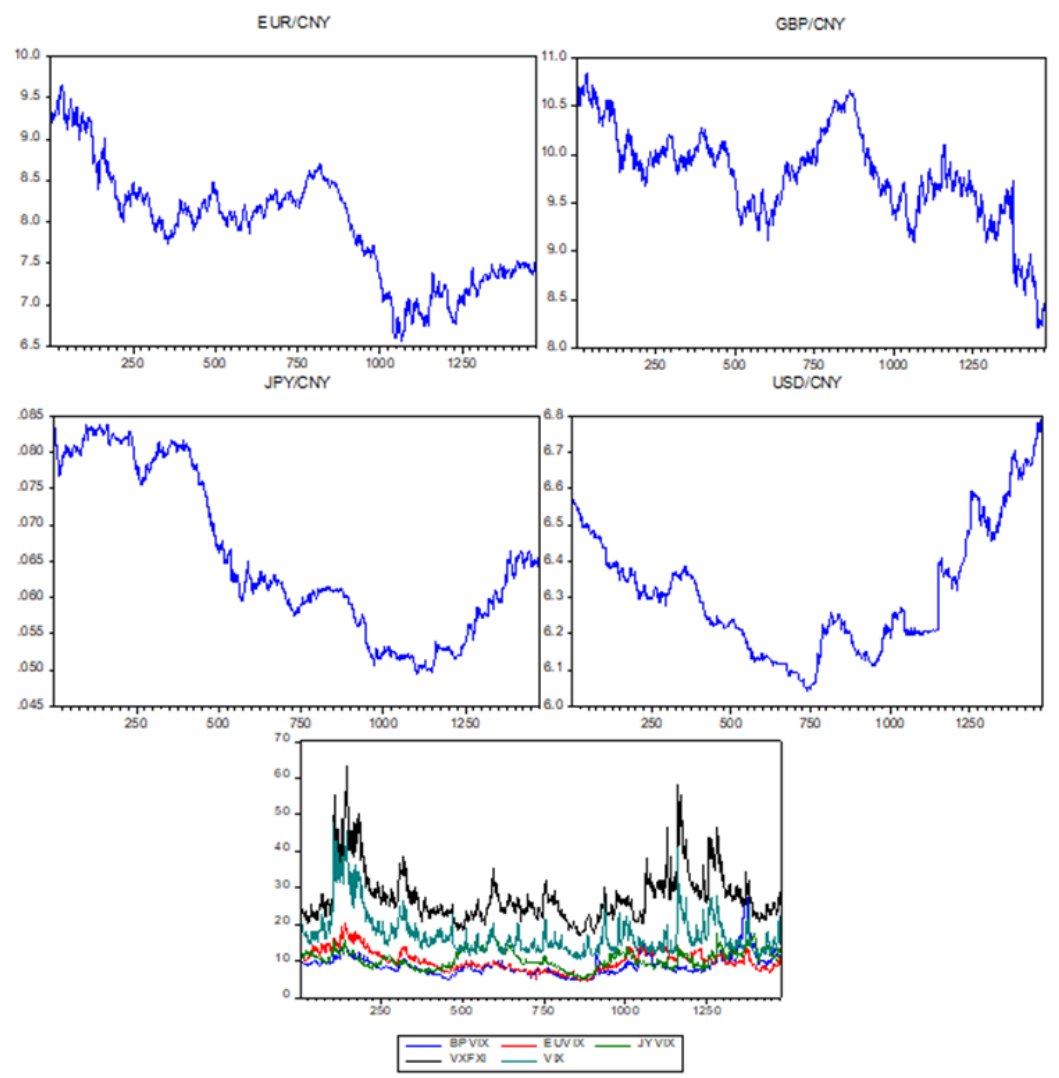

Figure 1: Level series of exchange rates and market volatility indices

\footnotetext{
${ }^{3}$ Variance Inflation Factor (VIF) is employed to authenticate results but not in the paper presented to conserve the space. 
Table 1: Descriptive Statistics and Unit Root Tests

\begin{tabular}{lccccc|cccccccc}
\hline & \multicolumn{4}{c}{ Implied Volatility Indices } & \multicolumn{3}{c}{ Foreign Exchange } & \multicolumn{3}{c}{ Bid-Ask Spread of Exchange Rates } \\
\hline & VXFXI & BPVIX & EUVIX & JYVIX & VIX & USD/CNY & GBP/CNY & EUR/CNY JPY/CNY|USD/CNY GBP/CNY EUR/CNY JPY/CNY \\
Mean & -0.0235 & 0.0036 & -0.0157 & -0.0182 & -0.0484 & 0.0022 & -0.0154 & -0.0144 & -0.0161 & 0.0658 & -0.1523 & -0.5993 & 0.3124 \\
Median & -0.3951 & 0.00 & 0.00 & 0.00 & -0.3619 & 0.00 & -0.0051 & -0.0049 & -0.0032 & 0.000 & 0.000 & 0.000 & 0.000 \\
Maximum & 36.576 & 28.671 & 26.542 & 30.106 & 40.546 & 1.8334 & 2.8532 & 2.8812 & 3.8964 & 460.51 & 415.88 & 283.32 & 259.02 \\
Minimum & -18.513 & -43.869 & -40.268 & -28.010 & -31.414 & -0.6877 & -7.5228 & -2.4407 & -3.4045 & -460.51 & -526.26 & -344.82 & -294.03 \\
Std. Dev. & 4.9418 & 4.3021 & 4.3631 & 4.7932 & 7.4492 & 0.1348 & 0.5455 & 0.5501 & 0.6089 & 88.871 & 70.133 & 62.496 & 64.453 \\
Skewness & 1.1674 & -0.5360 & -0.0851 & 0.2808 & 0.7489 & 1.8030 & -1.7765 & -0.0363 & 0.0184 & 0.0720 & -0.2193 & -0.2020 & -0.1957 \\
Kurtosis & 8.4112 & 15.437 & 10.830 & 7.2370 & 6.6486 & 30.736 & 28.197 & 5.2875 & 7.0854 & 7.5253 & 11.664 & 6.5319 & 5.6385 \\
Jarque-Bera & 2134.6 & 9577.3 & 3770.2 & 1122.7 & 956.08 & 48080.2 & 39794.6 & 321.92 & 1025.89 & 1112.09 & 4083.2 & 685.62 & 386.01 \\
Probability & 0.00 & 0.00 & 0.00 & 0.00 & 0.00 & 0.00 & 0.00 & 0.00 & 0.00 & 0.00 & 0.00 & 0.00 & 0.00 \\
Observations & 1475 & 1475 & 1475 & 1475 & 1475 & 1475 & 1475 & 1475 & 1302 & 1302 & 1302 & 1302 & 1302 \\
\hline ADF & -37.81 & -36.79 & -41.724 & -29.579 & -40.527 & -35.9839 & -38.397 & -37.4235 & -37.841 & -21.8368 & -18.4878 & -18.296 & -19.073 \\
Probability & 0.00 & 0.00 & 0.00 & 0.00 & 0.00 & 0.00 & 0.00 & 0.00 & 0.00 & 0.00 & 0.00 & 0.00 & 0.00 \\
\hline
\end{tabular}

\section{Methodology}

In the last decade, exchange rate volatility has been given much importance in economic journals (Busch, Christensen, \& Nielsen, 2012). Multiple pairs of the exchange rate with different frequencies has used a variety of volatility models, i.e., $A R C H$ and $G A R C H$. In this study, we employ asymmetric EGARCH $(1,1)$, model. The symmetric model GARCH $(1,1)$ was presented by (Bollerslev, 1986), and (Taylor S. , 1986). It is widely used than ARCH models because this model is more parsimonious and avoids overfitting and subsequently less likely to breach the nonnegativity constraint. We capture asymmetric effects using the EGARCH of (Nelson, 1991). The EGARCH model keeps two main advantages over simple GARCH model. The model takes into account log returns and gives positive conditional variance even if the parameters are negative. Secondly, the model allows capturing asymmetries known as leverage effect. The GARCH models estimate both conditional mean equation and conditional variance equation simultaneously.

$$
\begin{array}{ll}
d l y_{i t}=u+\sum_{i=1}^{m} \delta_{1} d l y_{i t-1}+\sum_{i=1}^{k} \delta_{2} x_{i t}+\varepsilon_{t} & \varepsilon_{t} \sim N\left(0, \sigma_{t}^{2}\right) \\
\sigma_{t}^{2}=\alpha_{0}+\alpha_{1} \varepsilon_{t-1}^{2}+\beta_{1} \sigma_{t-1}^{2} &
\end{array}
$$

Where (1) and (2) are mean and variance equations respectively. The term $y_{i t}$ indicate natural logarithmic returns of each exchange rate and bid/ask spread series, $u$ is a constant and $\varepsilon_{t}$ is error series. The term $y_{i t-1}$ represent lags of dependent variable to remove the problem of autocorrelation. The term $x_{i t}$ represent independent variables i.e. bid-ask spread of each exchange rate parity and respective implied volatility indices BPVIX, JYVIX, EUVIX, VXFXI and VIX. However, $\alpha_{1}$ is the coefficient of lagged squared residuals, $\varepsilon_{t-1}^{2}$ is the lagged squared residual from the mean equation and $\beta_{1}$ is the coefficient of the lagged conditional variance. It is important to note that $\alpha+\beta$ $<1$ ensures the stationarity of conditional variance. We use following specification Exponential $\mathrm{GARCH}(\mathrm{EGARCH})$ to capture asymmetric effects of time series.

$$
\ln \left(\sigma_{t}^{2}\right)=\omega+\beta \ln \left(\sigma_{t-1}^{2}\right)+\gamma \frac{\varepsilon_{t-1}}{\sqrt{\sigma_{t-1}^{2}}}+\alpha\left[\frac{\left|\varepsilon_{t-1}\right|}{\sqrt{\sigma_{t-1}^{2}}}-\sqrt{\frac{2}{\pi}}\right]
$$

Here, the parameter $\omega$ represents the long term average value. The coefficient $\gamma$ permits for asymmetries, since if the relationship between returns and volatility is negative, $\gamma$ will become negative implying that good news causes less volatility than bad news. We perform Ljung-BoxPierce Q-test up to $12^{\text {th }}$ lags and ARCH-LM test up to $5^{\text {th }}$ lags to verify that there is no autocorrelation and heteroscedasticity left in the residuals respectively.

Moreover, estimation of the models over sub-samples (full and pre-reforms) provides in itself a robustness. The residuals of the model also evidence the absence of serial correlation and heteroscedasticity. These robustness proofs enhance the reliability of our model assessments presented in this paper.

\section{Empirical Results}

The study is mainly categorized into following sections; first, we investigate the impact of implied volatility indices and respective bid-ask spread on CNY exchange rate parities concerning USD, 
EUR, GBP, and JPY. Second, we examine the impact of VIX indices on the bid-ask spread of exchange rates. Third, full sample, pre-reforms, and post-reforms samples are adopted due to reforms introduced in CNY exchange rate by Chinese monetary authorities on $11^{\text {th }}$ August 2015. However, Table 2 summarizes full sample, Table 3 pre-reforms and Table 4 offers post-reforms results of CNY exchange rate of mean and variance equations of $\mathrm{EGARCH}(1,1)$ model. Further, the results also indicate whether exchange rates and respective spread are associated with implied volatility indices at first moment (level) and second moment (variance level).

Table 2: Estimates of EGARCH(1, 1) Model

\begin{tabular}{|c|c|c|c|c|c|c|c|c|c|}
\hline & $\begin{array}{c}\text { Mean Eq. } \\
\text { Coefficients }\end{array}$ & $\begin{array}{l}\text { Variance Eq. } \\
\text { Coefficients }\end{array}$ & $\begin{array}{c}\text { Mean Cons. } \\
(u)\end{array}$ & $\begin{array}{l}\text { Variance } \\
\text { Cons. }(\omega)\end{array}$ & $\begin{array}{c}\text { ARCH } \\
(\alpha)\end{array}$ & $\begin{array}{c}\text { GARCH } \\
(\beta)\end{array}$ & $\begin{array}{c}\text { Asymmetric } \\
(\gamma)\end{array}$ & $Q(12)$ & $\begin{array}{c}\text { ARCH-LM } \\
(5)\end{array}$ \\
\hline \multicolumn{10}{|l|}{ EUR/CNY } \\
\hline EUVIX & $-0.0115^{\text {***}}$ & $2.2700^{* * *}$ & \multirow{4}{*}{-0.0001} & \multirow{4}{*}{$-0.0361^{* * *}$} & \multirow{4}{*}{$0.0184^{\star \star \star}$} & \multirow{4}{*}{$0.9979^{\star \star *}$} & \multirow{4}{*}{-0.0076} & \multirow{4}{*}{0.9209} & \multirow{4}{*}{0.6381} \\
\hline VXFXI & 0.0023 & 0.5056 & & & & & & & \\
\hline VIX & 0.0029 & $-0.5384^{*}$ & & & & & & & \\
\hline SPREAD & 0.0001 & $0.2589^{* \star *}$ & & & & & & & \\
\hline \multicolumn{10}{|c|}{ EUR/CNY SPREAD } \\
\hline EUVIX & 0.3588 & $-1.3356^{\star \star \star}$ & \multirow{4}{*}{0.0078} & \multirow{4}{*}{$-0.1582^{* * *}$} & \multirow{4}{*}{$0.1225^{\star \star \star}$} & \multirow{4}{*}{$0.9542^{\star * *}$} & \multirow{3}{*}{$-0.1385^{\star \star *}$} & \multirow{4}{*}{0.3113} & \multirow{3}{*}{0.8833} \\
\hline VXFXI & $0.6144^{*}$ & 0.4589 & & & & & & & \\
\hline VIX & -0.3005 & 0.1501 & & & & & & & \\
\hline \multicolumn{5}{|l|}{ GBP/CNY } & & & & & \\
\hline BPVIX & $-0.0265^{\star \star *}$ & $-0.9431^{\star \star *}$ & \multirow{4}{*}{-0.00006} & \multirow{4}{*}{$-0.6901^{\star * *}$} & \multirow{4}{*}{$0.1991^{\star \star \star}$} & \multirow{4}{*}{$0.9503^{* \star *}$} & \multirow{4}{*}{0.0028} & \multirow{4}{*}{0.4354} & \multirow{4}{*}{0.3684} \\
\hline VXFXI & $-0.0089^{* *}$ & 0.6178 & & & & & & & \\
\hline VIX & $-0.0056^{\star \star *}$ & $0.9802^{* \star *}$ & & & & & & & \\
\hline SPREAD & $-0.0003^{*}$ & $-0.1771^{\star \star \star}$ & & & & & & & \\
\hline \multicolumn{10}{|c|}{ GBP/CNY SPREAD } \\
\hline BPVIX & 0.0446 & $2.8844^{* * *}$ & \multirow{4}{*}{$0.0061^{*}$} & \multirow{3}{*}{$-0.4623^{* * *}$} & & & & & \\
\hline VXFXI & -0.5024 *** & $-4.5306^{\star * *}$ & & & $0.5353^{\star * *}$ & $0.9199^{\star * *}$ & $0.2009^{* * *}$ & 0.4629 & 0.8922 \\
\hline VIX & $0.2564^{* \star \star}$ & $1.0864^{* * *}$ & & & & & & & \\
\hline USD/CNY & & & & & & & & & \\
\hline VXFXI & $0.0022^{* * *}$ & $1.717^{* *}$ & & & & & & & \\
\hline VIX & -0.0003 & -0.3836 & $-1.91 \mathrm{E}-05$ & $-2.0118^{* \star *}$ & $0.4694^{* \star *}$ & 0.8788 & 0.0584 & 0.1178 & 0.5466 \\
\hline SPREAD & $0.0113^{*}$ & $57.356^{* \star *}$ & & & & & & & \\
\hline USD/CNY & PREAD & & & & & & & & \\
\hline VXFXI & $0.0029^{* * *}$ & $4.2385^{\star * *}$ & -000004 *** & $-00339 *$ & 00384 *** & $10006 * \star *$ & 02079 *** & 04601 & 09106 \\
\hline $\begin{array}{l}\text { VIX } \\
\text { IPYICNY }\end{array}$ & -0.0006 & $-3.2053^{\star \star \star}$ & & & 0.0004 & & 0.2019 & 0.4001 & 0.9100 \\
\hline $\begin{array}{l}\text { JPY/CNY } \\
\text { IYYIX }\end{array}$ & & & & & & & & & \\
\hline JYVIX & $-0.0056^{\star *}$ & $3.3112^{* \star *}$ & & & & & & & \\
\hline SPREAD & 0.0003 & $0.1553^{* * *}$ & -0.0001 & $-0.0647^{* \star *}$ & $0.0131^{\star \star}$ & $0.9948^{\star \star *}$ & $0.0107^{* *}$ & 0.9365 & 0.9732 \\
\hline VXFXI & $0.0101^{* * *}$ & 0.4884 & & & & & & & \\
\hline VIX & $0.0161^{* * *}$ & -0.3113 & & & & & & & \\
\hline JPY/CNY & READ & & & & & & & & \\
\hline JYVIX & -0.1431 & $0.7011^{*}$ & & & & & & & \\
\hline VXFXI & 0.5738 & 0.5853 & 0.0083 & $-0.1625^{\star \star *}$ & $0.1419^{\star \star \star}$ & $0.9617^{\star \star *}$ & 0.0177 & 0.9796 & 0.8723 \\
\hline$\underline{\text { VIX }}$ & -0.2899 & -0.0547 & & & & & & & \\
\hline
\end{tabular}

Table 2 reports full sample estimates whether implied volatility indices and exchange rate spread have a significant influence on CNY exchange rate parities at first moment in mean equation and second moment in variance equation. Empirical outcome evidence that most of the implied volatility indices have a significant negative influence on respective CNY exchange rate parities which turn exchange rates to appreciate. However, positive slopes of VXFXI and VIX in some cases point towards depreciation of respective exchange rates. This depreciation in exchange rates may be associated with an economic backdrop in the stock market crash, a slowdown in real GDP growth, and persistent capital outflows from Chinese markets in recent years (Peltier, 2015). This indicates implied volatility indices can play a significant role in forecasting exchange rates. The investors should consider VIX as 'fear-gauge index' during portfolio evaluation in foreign markets. Our results are consistent with the earlier literature (Kang, Ki-Hong, \& Yoon, 2014), (Kang, Yun-Jung, Ki-Hong, \& Sungkyun, 2014).

In theory, international trade is inversely correlated to the width of bid-ask spread and a rise in volatility widens spread in foreign exchange market. High volatility and widespread both discourage the active participation of traders in foreign exchange markets. Further, Table 2 reports the impact of bid-ask spread on respective exchange rates and also the effect of VIX indices on bid-ask spread. Spread illustrate significant negative influence on GBP/CNY exchange rate and VXFXI also affects bid-ask spread negatively which implies lower volatility and smaller spread both improve underlying exchange rate during the sample period. This, in turn, highlights the robustness of our 
results. On another side, USD/CNY spread bears positive slope (widespread) to affect the underlying exchange rate, and also VXFXI influences spread positively (high volatility) which implies high volatility and widespread both deteriorate USD/CNY exchange rate during the sample period. This positive association is consistent with (Glassman, 1987), (Boothe, 1988), (Black, 1989), and (Wei, 1991). However, Chinese monetary policy has remained dominant for recent periods and may have a direct impact on its specific volatility index. Hence VXFXI should be considered more effective and resourceful indicator than VIX.

Empirical outcomes of Table 3 and 4 present pre-reforms and post-reforms estimations of EGARCH $(1,1)$ model. Results show that VXFXI slope turns positive following post-reforms, which indicate that shift in exchange rate policy deteriorated EUR/CNY parity. Also, post-policy estimates exhibit the presence of leverage effect. In GBP/CNY exchange rate parity, VXFXI becomes insignificant in a post-reforms sample which implies that investors consider it irrelevant in forecasting respective exchange rate during post-reforms sample and prefer EUVIX and VIX for portfolio evaluation. In USD/CNY parity, VXFXI remains significant forecasting component with a positive slope which points toward depreciation of individual exchange rate. However, post-reforms bid-ask spread turns insignificant, and VXFXI also becomes less significant which may point toward a change in investor perception. The market participants perceive VXFXI as a more volatile indicator due to high standard deviation during the sample period. Finally, post-reforms estimates of JPY/CNY parity evidence the change in the slope of JYVIX. The slopes of VIX and VXFXI remain significantly positive in full, pre and post-reforms samples. Conclusively, respective implied volatility indices of exchange rates (EUVIX, GBVIX, and JYVIX) and VXFXI remain significantly important and reliable to forecast respective exchange rates in foreign exchange markets. The level and variance estimates of exchange rates and spreads indicate a significant relationship with VIX indices which implies that GARCH forecasts outperform in anticipating future volatility which is consistent with (Pilbeam \& Langeland, 2014). Also, post-reform sample assessments (which is considered as market-oriented exchange rate mechanism) evidence the rise in volatility in financial markets of China, which may discourage investor confidence and seeks for 'flight to safety. ${ }^{4}$ The market-oriented policies of China increased the forecasting capability of options volatility indexes to anticipate exchange rate dynamics from $2 \%$ to $5 \%$. This indicates that flexible exchange rate regimes lead to increase the predicting power of micro structural components.

Table 2, 3 and 4 further summarize the empirical results of $\operatorname{ARCH}(\alpha), \operatorname{GARCH}(\beta)$ and asymmetric parameter $(\gamma)$ of $\operatorname{EGARCH}(1,1)$ model and diagnostic tests. The values of ARCH $(\alpha)$, $\mathrm{GARCH}(\beta)$ terms identify the volatility persistence which is important in determining the relationship between returns and volatility as it verifies the alteration in risk premium (Devaney, 2001), (Saud Ahmed Khan, 2017). Empirical results evidence the presence of volatility persistence in $\operatorname{ARCH}(\alpha)$, and $\operatorname{GARCH}(\beta)$. The summation of $(\alpha)$ and $(\beta)$ in the GARCH models is generally less than one which indicate that returns generating process is featured by high the level of volatility persistence in conditional variance. Whenever, the value becomes closer to one, a shock will persist for many periods in future. A small value of $\alpha$ indicates that large market shocks induce comparatively small revisions in future volatility. While a high value of $\beta$ suggests that any shock to conditional variance takes longer time to disappear, hence volatility is persistent. The parameter $(\gamma)$ represent the occurrence of shock also known as leverage effect. The leverage effect is a negative correlation between past returns and future volatility of returns. Higher the leverage effect, greater would be the risk or volatility of a security. The higher leverage occurs due to negative returns which indicate lower security prices. In a nut shell, volatility parameters of variance equation ARCH $(\alpha), \operatorname{GARCH}(\beta)$ indicate the persistence of volatility and asymmetric parameter $(\gamma)$ shows absence of leverage effect in most exchange rate parities. However, post-reforms estimates exhibit the presence of leverage effect in EUR/CNY exchange rate and its bid-ask spread. Our results are consistent with earlier studies (Bala \& Asemota, 2013).

\footnotetext{
${ }^{4}$ Alan Greenspan favored the Chinese central bank's recent exchange rate depreciation move, regarding it an active step toward a market-oriented exchange rate mechanism, during his speech at the Brookings Institution on August 17, 2015. https://www.chinausfocus.com/finance-economy/why-fuss-over-rmb-depreciation
} 
Table 3: Pre-Reforms Estimation Results of EGARCH(1, 1) Model

\begin{tabular}{|c|c|c|c|c|c|c|c|c|c|}
\hline & $\begin{array}{c}\text { Mean Eq. } \\
\text { Coefficients }\end{array}$ & $\begin{array}{l}\text { Variance Eq. } \\
\text { Coefficients }\end{array}$ & $\begin{array}{c}\text { Mean } \\
\text { Cons. }(u) \\
\end{array}$ & $\begin{array}{l}\text { Variance } \\
\text { Cons. }(\omega) \\
\end{array}$ & $\begin{array}{c}\mathbf{A R C H} \\
(\alpha) \\
\end{array}$ & $\begin{array}{c}\text { GARCH } \\
(\beta) \\
\end{array}$ & $\begin{array}{c}\text { Asymmetric } \\
(\gamma)\end{array}$ & $Q(12)$ & $\begin{array}{l}\text { ARCH- } \\
\text { LM (5) }\end{array}$ \\
\hline \multicolumn{10}{|l|}{ EUR/CNY } \\
\hline EUVIX & $-0.0111^{\star \star *}$ & $2.5611^{* \star *}$ & \multirow{4}{*}{$-0.0002^{*}$} & \multirow{4}{*}{$-0.0094^{\star *}$} & \multirow{4}{*}{-0.0022} & \multirow{4}{*}{$0.9989^{\star \star *}$} & \multirow{4}{*}{-0.0028} & \multirow{4}{*}{0.6665} & \multirow{4}{*}{0.3267} \\
\hline VXFXI & $-0.0067^{\star}$ & 0.2165 & & & & & & & \\
\hline VIX & 0.0033 & $-1.0792^{\star \star *}$ & & & & & & & \\
\hline SPREAD & 0.0001 & $0.3531^{* \star *}$ & & & & & & & \\
\hline \multicolumn{10}{|c|}{ EUR/CNY SPREAD } \\
\hline EUVIX & 0.0257 & $-1.8411^{* \star *}$ & \multirow{4}{*}{-0.0028} & \multirow{4}{*}{-0.003} & \multirow{4}{*}{$0.0203^{* \star *}$} & \multirow{3}{*}{$1.0001^{* * *}$} & \multirow{3}{*}{$-0.5193^{\star \star *}$} & \multirow{3}{*}{0.2167} & \multirow{3}{*}{0.3441} \\
\hline VXFXI & $0.7406^{\star *}$ & -0.0853 & & & & & & & \\
\hline VIX & -0.1607 & 0.5752 & & & & & & & \\
\hline \multicolumn{7}{|l|}{ GBP/CNY } & & & \\
\hline BPVIX & $-0.0205^{\star \star *}$ & $1.2259^{* * *}$ & \multirow{4}{*}{$-0.0002^{\star \star}$} & \multirow{4}{*}{$-0.0949 * * *$} & \multirow{4}{*}{$-0.0208^{* *}$} & \multirow{4}{*}{$0.9893^{\star \star *}$} & \multirow{4}{*}{$-0.0914^{\star *}$} & \multirow{4}{*}{0.8728} & \multirow{4}{*}{0.5923} \\
\hline VXFXI & $-0.0093^{\star \star *}$ & $1.2269^{* \star \star}$ & & & & & & & \\
\hline VIX & $-0.0075^{\star * *}$ & -0.3751 & & & & & & & \\
\hline SPREAD & $-5.41 \mathrm{E}-05$ & 0.0383 & & & & & & & \\
\hline \multicolumn{10}{|c|}{ GBP/CNY SPREAD } \\
\hline BPVIX & 0.0254 & $0.9397^{* * *}$ & \multirow[b]{2}{*}{0.0048} & \multirow[b]{2}{*}{$-0.3269^{\star * *}$} & & & & & \\
\hline VXFXI & $-0.2758^{* *}$ & $-4.4788^{\star * *}$ & & & $0.3575^{\star \star \star}$ & $0.9397^{* \star *}$ & $0.0969^{\star *}$ & 0.4521 & 0.9185 \\
\hline USD/CNY & & & & & & & & & \\
\hline VXFXI & $0.0022^{* \star *}$ & $1.3064^{*}$ & & & & & & & \\
\hline VIX & -0.0003 & -0.4835 & $-0.00004^{* *}$ & $-1.7851^{\star * *}$ & $0.4254^{* * *}$ & $0.8941^{* * *}$ & $0.0510^{* *}$ & 0.3312 & 0.5529 \\
\hline SPREAD & $0.0139^{\star \star \star}$ & $64.3466^{\star * *}$ & & & & & & & \\
\hline USD/CNY & READ & & & & & & & & \\
\hline VXFXI & $0.0027^{\star \star \star}$ & $3.4867^{* \star \star}$ & $0,00005^{\star \star *}$ & $-3,0253^{* * *}$ & $13276^{* * *}$ & 08449 *** & 0,0431 & 0.2751 & 04951 \\
\hline $\begin{array}{l}\text { VIX } \\
\text { JPY/CNY }\end{array}$ & $-0.0012^{\star \star \star}$ & $3.4867^{* \star \star}$ & & & & & & & \\
\hline $\begin{array}{l}\text { JPY/CNY } \\
\text { JYVIX }\end{array}$ & $-0.0115^{\star \star *}$ & $4.0061^{* * *}$ & & & & & & & \\
\hline SPREAD & 0.0001 & $0.1576^{\star *}$ & & & & & & & \\
\hline VXFXI & $0.0071^{*}$ & 0.5781 & $-0.0003^{\star \star}$ & $-0.0476^{\star \star \star}$ & $0.0136^{\star \star}$ & $0.9964^{\star * *}$ & $0.0328^{\star \star \star}$ & 0.4695 & 0.9185 \\
\hline VIX & $0.0167^{* \star *}$ & -0.6165 & & & & & & & \\
\hline JPY/CNY & READ & & & & & & & & \\
\hline JYVIX & -0.2093 & 0.4292 & & & & & & & \\
\hline VXFXI & $0.9309^{* * *}$ & 0.3791 & -0.0072 & $-0.2452^{\star \star *}$ & $0.1631^{* * *}$ & $0.9283^{* * *}$ & $0.1085^{\star}$ & 0.9736 & 0.9189 \\
\hline VIX & -0.3763 & -0.2623 & & & & & & & \\
\hline
\end{tabular}

Table 4: Post-Reforms Estimation Results of $\operatorname{EGARCH}(1,1)$ Model

\begin{tabular}{|c|c|c|c|c|c|c|c|c|c|}
\hline & $\begin{array}{c}\text { Mean Eq. } \\
\text { Coefficients }\end{array}$ & $\begin{array}{l}\text { Variance Eq. } \\
\text { Coefficients }\end{array}$ & $\begin{array}{c}\text { Mean } \\
\text { Cons. }(u) \\
\end{array}$ & $\begin{array}{l}\text { Variance } \\
\text { Cons. }(\omega) \\
\end{array}$ & $\begin{array}{c}\text { ARCH } \\
(\alpha)\end{array}$ & $\begin{array}{c}\text { GARCH } \\
(\beta) \\
\end{array}$ & $\begin{array}{c}\text { Asymmetric } \\
(\gamma)\end{array}$ & $Q(12)$ & $\begin{array}{l}\text { ARCH- } \\
\text { LM (5) }\end{array}$ \\
\hline \multicolumn{10}{|l|}{ EUR/CNY } \\
\hline EUVIX & $-0.0231^{\star \star *}$ & $4.6171^{\text {** }}$ & \multirow{4}{*}{-0.0001} & \multirow{4}{*}{$-6.4338^{\star \star *}$} & \multirow{4}{*}{$0.5958^{\star \star *}$} & \multirow{4}{*}{$0.4372^{\star \star \star}$} & \multirow{4}{*}{$-0.1601^{*}$} & \multirow{4}{*}{0.8298} & \multirow{4}{*}{0.1066} \\
\hline VXFXI & $0.0196^{\star \star}$ & $3.2137^{*}$ & & & & & & & \\
\hline VIX & -0.0019 & $-1.8793^{\star *}$ & & & & & & & \\
\hline SPREAD & 0.0003 & $0.2451^{*}$ & & & & & & & \\
\hline \multicolumn{10}{|c|}{ EUR/CNY SPREAD } \\
\hline EUVIX & $1.8439^{* * *}$ & 3.1161 & \multirow{3}{*}{0.0112} & \multirow{3}{*}{$-2.1644^{\star \star \star}$} & \multirow{3}{*}{0.1796} & \multirow{3}{*}{$-0.3945^{\star *}$} & \multirow{3}{*}{$-1.4631^{\star \star \star}$} & \multirow{3}{*}{0.5243} & \multirow{3}{*}{0.4761} \\
\hline VXFXI & 0.7252 & -0.9896 & & & & & & & \\
\hline VIX & $-0.7696^{\star *}$ & 0.5979 & & & & & & & \\
\hline \multicolumn{10}{|l|}{ GBP/CNY } \\
\hline BPVIX & $-0.0524^{* * *}$ & $-4.8185^{\star * *}$ & \multirow{4}{*}{-0.0001} & \multirow{4}{*}{$-3.0962^{\star \star *}$} & \multirow{4}{*}{$0.2082^{\star \star}$} & \multirow{4}{*}{$0.7260^{\star \star *}$} & \multirow{4}{*}{0.0271} & \multirow{4}{*}{0.4146} & \multirow{4}{*}{0.8855} \\
\hline VXFXI & -0.0121 & -1.1712 & & & & & & & \\
\hline VIX & $0.0125^{*}$ & $2.6268^{* *}$ & & & & & & & \\
\hline SPREAD & -0.0005 & $-0.5662^{\star \star *}$ & & & & & & & \\
\hline \multicolumn{10}{|c|}{ GBP/CNY SPREAD } \\
\hline BPVIX & $-0.1134^{\star \star *}$ & $6.4074^{\star \star \star}$ & \multirow{2}{*}{$-0.0035^{\star \star *}$} & \multirow{2}{*}{$-0.9598^{\star \star *}$} & & & & & \\
\hline VXFXI & $0.0627^{* * *}$ & $-13.6207^{* \star *}$ & & & $1.6127^{\star \star *}$ & $0.9865^{* * *}$ & -0.0096 & 0.4892 & 0.8955 \\
\hline USD/CNY & & & & & & & & & \\
\hline VXFXI & $0.0036^{*}$ & $3.7699^{*}$ & & & & & & & \\
\hline VIX & -0.0018 & -0.178 & 0.0001 & $-4.5689^{\star * \star}$ & $0.4201^{\star * *}$ & $0.6751^{* * *}$ & -0.0926 & 0.2781 & 0.8662 \\
\hline SPREAD & -0.0131 & 31.031 & & & & & & & \\
\hline USD/CNY & READ & & & & & & & & \\
\hline VXFXI & $0.0029^{* \star \star}$ & $-2.6879^{* *}$ & 0.0001 *** & $-0.2033^{* *}$ & 0.0891 *** & $09846 * * *$ & $05637^{* * *}$ & 03767 & 09878 \\
\hline VIX & $-0.0015^{\star *}$ & -0.0158 & 0.0001 & -0.2033 & ( & 0.9040 & 0.5031 & 0.0101 & 0.9818 \\
\hline JPY/CNY & & & & & & & & & \\
\hline JYVIX & $0.0153^{* * *}$ & $3.1326^{\star \star *}$ & & & & & & & \\
\hline SPREAD & $0.0011^{* *}$ & $0.3549^{* * *}$ & 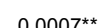 & $=03033 *$ & $1505^{\text {** }}$ & 0 9812*** & 00739 ** & 07058 & O 3568 \\
\hline VXFXI & $0.0213^{* *}$ & 0.0498 & $0.0007^{m a}$ & $-0.3033^{n}$ & $0.1505^{n}$ & $0.9812^{n n}$ & $-0.0739^{n}$ & 0.1058 & 0.3568 \\
\hline VIX & $0.0143^{\star *}$ & -0.6219 & & & & & & & \\
\hline JPY/CNY & READ & & & & & & & & \\
\hline JYVIX & -0.7999 & -1.1391 & & & & & & & \\
\hline VXFXI & $-3.0206^{\star \star *}$ & $7.2868^{\star *}$ & -0.0223 & $-0.4261^{\star \star *}$ & $0.3121^{\star \star *}$ & $0.8104^{* * *}$ & -0.2367 & 0.1274 & 0.4705 \\
\hline VIX & $1.5124^{* *}$ & -0.7601 & & & & & & & \\
\hline
\end{tabular}




\section{Conclusion}

This study examines the intertemporal association between CBOE market volatility indices (VIX), foreign exchange rates and their respective bid-ask spread for four CNY parities concerning worldleading currencies; United State Dollar (USD), the Euro (EUR), the British Pound (GBP) and the Japanese Yen (JPY). For this purpose, the study utilizes the stylized EGARCH $(1,1)$ model for the period of 2011 to 2016. The sample period includes a policy break in CNY exchange rate. Hence sample is divided into three parts, full-sample, pre and post-reforms.

The study finds that CNY exchange rate parities are globally recognized and significantly influenced by both global volatility index (VIX) and volatility index of Chinese exchange-traded funds (VXFXI) which suggest that VIX can act as 'fear gauge' indicator and its potential direction may guide investors in anticipating the movements of CNY exchange rate parities. However, the negative slopes of EUVIX, BPVIX, and JYVIX indicate that a higher level of VIX improves the appreciation of particular exchange rate, but positive slopes of VXFXI deteriorates exchange rate during the sample period. The market-oriented policies of China increased the forecasting capability of options volatility indexes to anticipate exchange rate dynamics from $2 \%$ to $5 \%$. This indicates that flexible exchange rate regimes lead to increase the predicting power of micro structural components. Similarly, high volatility widens bid-ask spread which deteriorates respective exchange rate, while low volatility reduces bid-ask spread which improves underlying exchange rate parity. The volatility estimates of variances show the persistence of volatility and absence of leverage effect among most exchange rates. However, there is no asymmetry in response to the good or bad news in response to implied volatility. Moreover, respective implied volatility indices of exchange rates (EUVIX, GBVIX, and JYVIX) and VXFXI remain significantly important and reliable to forecast respective exchange rates in foreign exchange markets. The level and variance estimates of exchange rates and spreads indicate a significant relationship with VIX indices which implies that GARCH forecasts outperform in anticipating future volatility. Also, post-reforms assessments evidence the rise in volatility in financial markets of China, which may discourage investor confidence and seeks for 'flight to safety.'

These outcomes provide important implications for implementing financial policies and guide investors in portfolio evaluations. The present study may guide monetary institutions to explore the mechanics of various exchange rate parities of trading partner countries. The future research can accommodate the impact of composite implied volatility index which is highly correlated with VIX to authenticate the impact on these exchange rate parities. Also, future research may consider the impact of VIX and VXFXI on financial markets of other countries which will be supportive for global investors to anticipate other financial markets.

\section{Acknowledgement}

This research is funded by China National Social Science Foundation, Project number: 15BGJ037

\section{References}

Bala, D. A., \& Asemota, J. O. (2013). Exchange-Rates Volatility in Nigeria: Application of GARCH Models with Exogenous Break. CBN Journal of Applied Statistics, Vol.4 No.1.

Black, S. W. (1989). Transaction costs and vehicle currencies. IMF working paper, WP/89/96.

Bollerslev, T. (1986). Generalized Autoregressive Conditional Heteroscedasticity. Journal of Econometrics, vol 31, no 3, pp.307-327.

Boothe, P. (1988). Exchange rate risk and the bid-ask spread: A seven country comparison. Economic Inquiry, Vol. 26, p. 485-492.

Busch, T., Christensen, B. J., \& Nielsen, M. $\varnothing$. (2012). The role of implied volatility in forecasting future realized volatility and jumps in foreign exchange, stock, and bond markets. Journal of Econometrics, Vol 160, no 1, pp.48-57.

Cairns, J., Ho, C., \& McCauley, R. (2007). Exchange rates and global volatility: implications for Asia-Pacific currencies. BIS Quarterly Review, March.

Devaney, M. (2001). Time varying Risk Premia for Real Estate Investment Trusts: A Garchm Model. The 
Quarterly Review of Economics and Finance, Vol 41- 335-346.

Engle, R., \& Patton, A. (2001). What is a good volatility model? Quantitative Finance, vol 1, no 2, pp.237-245.

Fleming, J., Ostdiek, B., \& Whaley, R. E. (1995). Predicting stock market volatility: A new measure. Journal of Futures Markets, 15, 265-302, May 1995

Flood, R. P., \& Taylor, M. P. (1996). Exchange Rate Economics: What's Wrong with the Conventional Macro Approach? National Bureau of Economic Research, p. 261 - 302.

Frankel, J. A., \& Rose, A. K. (1994). A survey of empirical research on nominal exchange rates. National bureau of economic research, Working Paper No. 4865.

Frankel, J., \& Froot, K. (1990). Chartists, Fundamentalists, and Trading in the Foreign Exchange Market. American Economic Review, vol. 80, issue 2, 181-85.

Glassman, D. (1987). Exchange rate risk and transactions Costs: Evidence from bid-ask spreads. Journal of International Money and Finance, p. 479-490.

Kang, S. H., Ki-Hong, C., \& Yoon, S.-M. (2014). The impact of global volatility on Asian financial markets. Korea: National Research Foundation.

Kang, S. H., Yun-Jung, L., Ki-Hong, C., \& Sungkyun, P. (2014). The Impact of Global Volatility on Korean Financial Markets. International Conference on Trends in Economics (pp. Aug 13-14). Pattaya (Thailand): Humanities and Management (ICTEHM'14).

Krugman, P., \& Miller, M. (1991). Target zones and exchange rate dynamics. Quarterly Journal of Economics, 106, No. 3:669-82.

Lyons, R. K. (2001). The Microstructure Approach to Exchange Rates. Cambridge and London: MIT Press.

Meese, R., \& Rogoff, K. (1983). The Out-of-Sample Failure of Empirical Exchange Rate Models: Sampling Error or Misspecification? National Bureau of Economic Research, p. 67 - 112.

Nelson. (1991). Conditional heteroskedasticity in asset returns: A new approach. Econometrica, Vol 59, no 2, pp.347-370.

Nie, J., Zhang, Z., Zhang, Z., \& Zhou, S. (2015). Currency Exposure in China under the New Exchange Rate Regime: National Level Evidence. China \& World Economy, Volume 23( Issue 3, May-June 2015), pages 97-109.

Peltier, C. (2015). China: A new exchange rate policy. P. 22-234th quarter 2015. economicresearch.bnpparibas.com: BNP PARIBAS.

Pilbeam, K., \& Langeland, K. N. (2014). Forecasting exchange rate volatility: GARCH models versus implied volatility forecasts. International Economics and Economic Policy, doi: 10.1007/s10368-014-0289-4.

Sarwar, G. (2012). Is VIX an Investor Fear Gauge in BRIC Equity Markets? Journal of Multinational Financial Management, Vol. 22, pp. 55-65.

Saud Ahmed Khan, M. K. (2017). Comparative Risk and Return Analysis of Islamic and Conventional Financial Institutions in Pakistan. International Journal Of Islamic Economics And Finance Studies, Vol:3, Issue: 1.

Taylor, M. P. (1995). The Economics of Exchange Rates. Journal of Economic Literature, Vol. 33, No. 1, pp. 1347.

Taylor, S. (1986). Modelling Financial Time Series. Chichester: John Wiley \& Sons, Ltd.

Wei, S. J. (1991). Anticipation of Foreign Exchange Volatility and Bid-Ask Spread. International Finance Discussion Papers, Federal Reserve System, Number 409.

Whaley, R. E. (2000). The Investor Fear Gauge. The Journal of Portfolio Management, 26(3):12-17 · March 2000.

Yang Cheng Lu, Y. C. (2012). Nonlinear Dynamics between the Investor Fear Gauge and Market Index in the Emerging Taiwan Equity Market. Emerging Markets Finance \& Trade, Vol. 48, pp. 171-191. 


\section{Appendix}

Plots of return series of exchange rates, market volatility indices and bid-ask spread of exchange rates
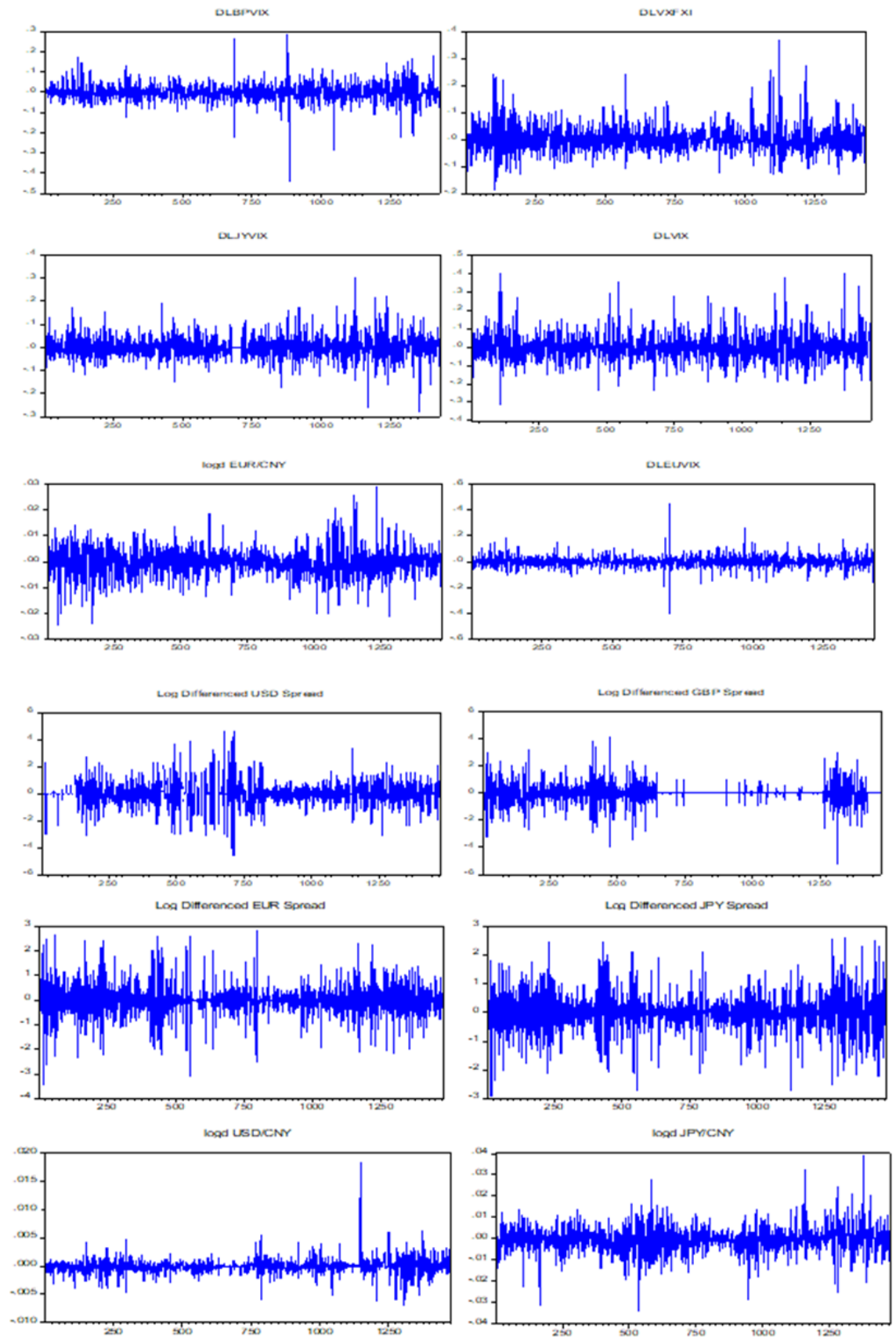